\title{
Macroeconomic Situations and Policy Adjustments in China
}

\author{
Dongjun Mao \\ Graduate School of Chinese Academy of Social Sciences \\ Beijing 100102, China \\ E-mail: maodongjun@gmail.com
}

\begin{abstract}
China has achieved wholly rapid growth, with economic reform and opening-up, since 1978. But the macro-economy is instable and showing prosperity and inflation, and Recession and deflation repeatedly with many times. Excessive fluctuations in the economy are due to macroeconomic policies' amendments and adjustments, too loose or tight. Economic growth speeds up with macroeconomic fluctuations slowing down in recent years. Improvements in macroeconomic policies have played an important role. 2008 global financial turmoil, Because of the financial crisis in U.S., China's economy came to a standstill, and the relative policies were made with emergent adjustments. It is reasonable and essential that macroeconomic policy are amended and adjusted whether or not China's economy can overcome the crisis as soon as possible.
\end{abstract}

Keywords: Macro economy, Market-oriented reform, Macroeconomic policy's adjustments and amendments, Monetary policy

\section{Introduction}

There being two serious economic overheating and inflation, with the economic situation dropped sharply when tighter economic policies taken, the magnitude of economic fluctuations, up and down, is serious, in the first twenty-five years (1978-2002) since reform and opening-up. The first time, in 1987 and 1988, GDP growth rate rose to $11.6 \%$ and $11.3 \%$ in 1988 and 1989 the consumer price index (CPI) rose to $18.8 \%$ and $18 \%$. After tighter economic policies were taken, the GDP growth rate in 1989 dropped to $4.1 \%$, followed with a significant decline of $7.2 \%$ in 1991 , CPI dropped to $3.1 \%$ declined by nearly $15 \%$. The second time, from 1992 to 1994 , GDP growth rate rose to $13 \%$ with CPI rose to $24.1 \%$. With tighter economic policies were taken, the growth rate in 1999 dropped to $7.6 \%$, representing a decrease of $6.6 \%$ in the peak year, and CPI, inflation turned into deflation, dropped to $-1.4 \%$ in the same year(Figure 1 ).

Insert Figure 1 here

Fluctuations in investment in fixed assets and retail sales are greater, measured in the current prices. In the first time, growth rate in the fixed-asset investment rose to $38.8 \%$ and $25.4 \%$, retail sales increased to $27.5 \%$ and $27.8 \%$, then, respectively, fell to $-7.2 \%$ and $8.9 \%$, decreased by $38.6 \%$ and $18.9 \%$ than the previous year after the policy. In the second time, growth in the investment in fixed assets and retail sales rose to $61.8 \%$ and $29.8 \%$ after the policy in 1999 , the rate, respectively, dropped to $5.1 \%$ and $6.8 \%$, by $56.7 \%$ and $23 \%$ compared with the peak value just a few years ago.

\section{Fluctuations in Economy with Improper Monetary Polices' Adjustments}

Excessive fluctuations in macro economy are mainly due to the instability in macroeconomic policies, improper monetary policy, too loose or too tight. From 1984 to 1987, monetary policies were adjusted loosely, the growth rate of M2 increased to $24 \%-31 \%$, promoting rapidly economic growth with inflation.

After tighter economic policies were taken in 1988 and 1990, growth rate in M2 dropped to 13\%, with a significant decline in economic growth, the rapid lowering prices. In 1992 and 1993, a much more loose monetary policy was taken, M2 growth rate increased to $31 \%$ and $37 \%$, ultra-and-high speed in economic growth, leading to more serious inflation. From 1998 to 2000 , M2 growth rate reduced to $12 \%$, resulted in the excessive decline in the economy, and inflation turned into deflation by monetary policies tighten (Figure 2).

Insert Figure 2 here

Administrative policies were taken in order to control over prices and investment. From 1985 to 1988, the period of 
rising prices and increasing investments, the State Council issued a direction on local authorities and asked them to take administrative measures to control prices and compressing the scale of investment. Macroeconomic management increased administrative policies, with strict examination and approval of investment to compress the scale with strict credit control policies in September 1988. Fixed-asset investment growth rate in 1989 dropped to $-7.2 \%$, CPI dropped to $3.1 \%$ percent, lower than the $14.9 \%$ over the previous year, retail sales dropped to $2.5 \%$, GDP growth rate dropped to $3.1 \%$. Strong administrative rules and tighter monetary policies, resulted in hard landing for the economy, rapid economic growth slipped to the bottom, from a macroeconomic overheating over a short period into the cold.

In 1993, when the CPC Central Committee and State Council in June adopted a "Views over CPC Central Committee and State Council on the current economic situations and strengthening of macro economy" to exert strictly control upon the issuance of credit, liquidity or cessation of bank lending, corporate activities in financial markets, and strict control over investment in real estate, strengthen tax collection and management, clean up audit of investment projects under construction, and strictly control new projects, and so on. Activities in the financial markets were severely crack down, many investments in bonds, equity and trust were banned, many corporate loans were recovered ahead of schedule. The collapse of the real estate bubble appeared in the coastal areas, and a number of financial institutions went bankruptcy. Large number of bad debts existed in enterprises and financial institutions, after the period of have which had long-term adverse effects on the financial and economic operations and developments.

The second half of 1993, Macroeconomic administration began to introduce tighter policies, which were not only improvements, but also mistakes compared to 1988. Improvement lied in the fact that macroeconomic administration took steps to tighten the policies gradually in a few years, not the rapid tightening of monetary loans in place by taking the absorption of the lessons of a hard landing in 1988. From 1993 to 1997, M2 growth gradually slowed down from $37.3 \%$ to $25.3 \%$ from $24.1 \%$, inflation rate fell to $8.3 \%$, investment growth slowed from $61.8 \%$ percent to $14.8 \%$, GDP growth rate dropped steadily from $14 \%$ to $10 \%$. Macro economy gradually lowered to achieve a soft landing. Error lied in the fact that macroeconomic administration continued to strengthen the crunch, and caused the excessive decline in the economy after the goal of soft landing achieved. In 1997, GDP growth and inflation rate down to $9.3 \%$ and $2.8 \%$, investment growth rate to $8.8 \%$. Macroeconomic indicators had dropped to the normal range or below normal levels. But the tighter policies still continued, especially tighten monetary loans. From 1997 to 1999, M2 growth fell from 19.6\% to $14.7 \%$, CPI dropped to $-1.4 \%$, growth rate in the investment and GDP dropped to $5.1 \%$ and $7.6 \%$, which were in a low level.

From 1998 to 2002, tighten macroeconomic continued and resulted in deflation and macro economy downwards, not to release vigilance against inflation. Monetary policy authorities did in accordance with the growth of money supply not exceeding $15 \%$, CPI not exceeding the goal of zero to tighten monetary policy. In the five years, the majority of the months, growth rate of M2 and loan contracted to $15 \%$ or less, CPI was down to the negative (Figure 3). The risk of inflation was eliminated, but deflation appeared to bring about consumption and investment downwards, and unemployment was serious with social problems increased. Growth rate in retail sales feel to $7 \%$ and fixed-asset investment dropped to $5.1 \%$. The registered urban unemployment rate was from $3.1 \%$ to $4 \%$.

\section{Insert Figure 3 here}

\section{Market-oriented reforms and Macroeconomic policies' adjustments}

Since 1978, China's economy has entered a new period of market-oriented reforms and economic quickly developments. Economic growth has been accelerating, because the old central-plan mechanical economy was breakdown, which impulse the decentralization and reform of enterprises to expand their powers to stimulate the local economies active and business vital. The early stage, the first ten years, of reforms and opening-up, macroeconomic administration exerted a relatively flexible monetary policy wholly, implementing adequate monetary support market-oriented reforms and rapid economic developments. Local governments and enterprises had enthusiasm to investment. Income of urban and rural residents, especially the rural residents were on the increase rapidly with the emergence of consumption boom in housing and appliances. Vitality of local governments and the competitiveness of enterprises, lack of restraint mechanisms, led to excessive expansion of investment scale. The market-oriented reform, especially the price-settle mechanism, brook through the price-control system. In 1988, a striking rise in the prices of consumption goods. This not only released money supply, but also contained reforms in the price-settle mechanism, which exerting, on the one hand, the formation of the negative impact of inflation, on the other hand, having market-oriented reforms positively. In the fourth quarter of 1988, macroeconomic administrations adopted tighter monetary policy to decelerate quick investments and inflation trend, stabilizing the macroeconomic situation, at the same time, making stagnation and retrogression of market-oriented reforms.

Market economic system was decided to establish to achieve rapid economic growth, which means market-oriented reforms were entering a new stage in 1992. Policy of release of substantial monetary supply was striking. Local economies and cooperates rapidly expanded business investments. Economy showed rapid increases in the consumption of residents, a new round of investment on the increase and inflation. The second half of 1993, macroeconomic 
administration began to tighten economic policies, the more relative tight fiscal policy and monetary policy. In 1994, macroeconomic administration continued to advance tax, financial system, investment mechanism and enterprise reforms, at the same time, promoting reforms in the fields of health care, education, social security, and housing. These reforms promoted macroeconomic management system to change from a planned economy to a market economy, learning from the mature market economies and macro-management mode, establishing the policy and governance structure of monetary and fiscal policy. The central bank, changed from People's Bank of China, was responsible for the formulation and implementation of monetary policy. Reforms in the tax system, instead of local financial system, increased the concentration of the central finance. The central bank used tools as deposit reserves, open market operations, and rediscount rates to exert monetary policies, reducing the scale of loans from the commercial banks lending controls and direction loans, and gradually pushed forward market-oriented reform of interest rates in order to make monetary policy play a central role in the conditions of market economy system. The duty of State Development Planning Commission changed from mainly the distribution of goods and approval of investment projects into responsibly formulating economic and social development plans and industrial and regional policies in the long term, with the coordination of ministry of finance with the central Bank.

In 1995, macroeconomic administration decided to execute the moderately tight fiscal policy and monetary policy, which not only for short-term policy to control the inflation, but also the impulse for investment in institutional and economic reforms in the medium and long terms. The moderately tight macroeconomic policies, purpose to take urgent rules for economic situations were proposed for the first time, which were repeated in the Directory Plan for long-term development of the fifteen years (1996-2010) by the CPC Central Committee. Macroeconomic administration and the academic community generally believed that China's economy was in the transitory stage of market-oriented reforms, lack of an effective mechanism of risk for investment and financial activities, have not yet established, financing There being soft constraints in The financial relationship, which might be prone to impulse aimless investment and economic overheating, between state-owned enterprises and state-owned banks. It was difficult to solve, as a systematic and mechanic problem, in the short term. So, it was proper to execute the moderately tight Macroeconomic policies in the long term. The tight macroeconomic policies included tighter fiscal policy and tighter monetary policy. But, in the macroeconomic management practice, fiscal policy actually was not tight by expanding policies such as issuing governments' bonds. So, the tighter macroeconomic policies always mean tighter monetary policy, once mentioned in the development plan of the CPC Central Committee in the long-term which had a strong authority that was not doubted absolutely in the next fifteen years. Tighter monetary policy lasted over years. Reforms in depth, such as investment and financial system, enterprise mechanism, income distribution policy, labor markets, social security, health care, and so on, formed gradually risk constraints, which provided microeconomic foundation to execute the tighter monetary policy.

China's economy, achieved the soft landing goal in 1996, was affected by the financial crisis in Southeast Asia, in 1997, leading to the impact of declining exports and economic growth. It became obsolete to maintain the tighter monetary policy, which the main goal to control inflation. Nominally so-called solid monetary policy, actually was implementing more severe tightening. Growth rate of M2 was reduced from 20\% to 19.6\% lower 5.7\%than the last year, then beneath $15 \%$ in the four years. Fiscal policy was taken by issuing government bonds, and the expansion of investment. From 1998 to 2002, Treasury issued 660 billion yuan of treasury bonds, including matching funds, totally 3.2 trillion yuan of investment scale, about $18.6 \%$ of total social investment. Expansive fiscal policy with the tighter monetary policy did not play a lead role in total investment, but increase the proportion of government investment, with a crowding-out effect of other investment. Growth rate in fixed-asset investment and consumption retails decreased obviously in current prices. Growth rate of investment was down to $8.8 \%$ lower by $6 \%$ over the previous year in 1997 , then down to $5.1 \%$ in 1999. Growth rate of consumption retails in 1997 reduced to $10.2 \%$ in 1998 and 1999 down to $8.8 \%$. CPI dropped to $-0.8 \%$ in 1998 and $-1.4 \%$ in 1999 , with a slight upwards in 2000 and 2001 , and then dropped to $-0.8 \%$ in 2002 . The degree of tighter monetary policy was continuing to strengthen, enterprises' normal operations and developments faced with a serious shortage of funds, with a significant decrease of market demand and increasing business risk of losses and bankruptcy.

Market-oriented reforms started from the change from the system of incentives in profits into strengthen the constraints to overcome the soft constraints. State-owned enterprises, particularly, a few large enterprises got special policy supports. Private-owned enterprises were discarded, actually, with worse financial and operational business environments. In order to reduce over-burdened social issues, State-owned enterprises made a large number of employee layoffs. It was difficult to find new jobs for these unemployed who lacked subsidies and allowances, leading a hard life. Although reforms of State-owned enterprises aimed at establishing a medical care, retirement, unemployment and other social security systems, which placed emphasis on excessive social burdens, workers had to afforded their health care and retirement insurances at their own expense of high percent. Reforms, in education industrialization and commercialization of housing, increased significantly households' expenditure on their children's education and living burdens. But, majority of workers' incomes grew slowly, the slow growth of wages, Aggravating gap between income and expenditure led to many of the actual level of lives reduced. Income distribution changed from the early stage of 
reform over national income decreasing and enterprises and personal income increasing into national income increasing and business and personal income falling. Risk of excessive economic and social pressures were assumed by businesses and individuals resulted in a sharp weakening of demand in business investment and consumption. Strengthened Effect of tighter monetary policy did slow down economic growth, deflation, rise unemployment, and increase hardships of the people. From 1998 to 2002, Macroeconomic indicators, On the whole, deteriorated. Average growth rate of GDP fell to $8.2 \%$. The registered urban unemployment rate rose to $4 \%$, and those unemployed not registered were even worse. Trouble-making events, made by groups of layoff, occurred in many places. Situations of low growth and high unemployment predicated that it was difficult to continue the tighter of monetary policy.

\section{Rapid Economic Growth with Proper Monetary Policy}

In 2003, Policy showed the apparent shift in macroeconomic policies from controlling over-investment and accelerating inflation to support economic growth rapidly. The growth rate of the currency loans increased substantially, from the performance of actual monetary implementation, although so-called the moderately tight monetary policy. Growth rate in M2 and loans increased by $19.6 \%$ and $21.1 \%$, higher than the previous year, by $2.7 \%$ and $5.3 \%$, respectively, in 2003 . From 2003 to 2007, the average of growth rate in M2 and loans by $16.9 \%$ and $16 \%$, on the average, higher by $1.6 \%$ and $1.2 \%$ than the period from 1998 to 2002. Released monetary policy supported investment, consumption, exports and overall GDP growth rate on the increase trend. Consumption retails, fixed-asset investment, exports increased by average of $13.2 \%, 25.8 \%$ and $30.3 \%$ in current prices, higher than the previous five years by $4.2 \%, 14 \%$, and $17.6 \%$, respectively, GDP growth rate $10.8 \%$ on average, higher than the previous five years by $2.6 \%$. Consumer price index changed from the decline trend into a moderate rise in the range of $1 \%-3 \%$. Residents' situations improved in employment, income, consumption. The registered urban unemployment rate declined from $4.3 \%$ in 2004 to $4 \%$ in 2007. From 2003 to 2007, five years, disposable income of urban residents and rural residents, increased, respectively, $9.8 \%$ and $6.8 \%$, respectively, higher than the previous five years, $1.1 \%$ and $3 \%$.Urban and rural consumption expenditure per capita grew by $8.1 \%$ and $7.9 \%$, respectively, higher $0.2 \%$ and $4.9 \%$ than the previous five years (Table $1)$.

\section{Insert Table 1 here}

\section{Scholars' Debates}

Adjustments in macroeconomic policies and changes in economic operations invoked departments and the academic debates and arguments since 2003. Many people thought that main macroeconomic indicators raised too faster, macroeconomic situation of overheat was beyond the reasonable boundaries. Macroeconomic administration had issued its own warnings that economy had been its partial heat and changing from the partial path to the overheating trend. From 2003 to 2007, the GDP growth, on average, was $11 \%$, up to $13 \%$ in 2007, substantially in excess of the average growth rate of three decades of reforms and opening-up, close to 1985 and 1993, which were periods of serious economic overheating and inflation. Growth rate in fixed asset investment was $25 \%$, exceeded the average level in the first five years of more than $10 \%$, and resulted in tighter supply of coal, electricity and oil and other goods, with investment goods prices rising. Export growth of $25 \%-35 \%$, resulted in too large trade surplus and foreign currencies inflow, which lead to excessive money supply passively about $16 \%$ more than the strict control line of $15 \%$,application of tightening monetary policy since 1998.

Experts of Development and Reform Commission believed that in 1998 five years after the implementation of tight monetary policy, economy, growth rate around $8 \%$, did not appear overheated, but a appropriate rate of economic growth, although investment in some industries and enterprises showed with the aimless expansions. Some experts argued that excessive growth of investment in steel, cement and electrolytic aluminum, which were caused by exceeding demand and high profits lead to accelerating investment, aimless expansion and serious overcapacities would deduce huge wastes and serious depression since 2003. The central bank expressed that trend of continuing higher prices in iron and steel, coal, non-ferrous metals, chemical raw materials, and capital goods, would changed into a cost-push inflation trend, which indicating that excessive growth of monetary credit, resulting in an overheated situation and inevitable inflation in consequence.

Wide attentions, with criticisms, were paid on rapid growth in energy consumptions and environmental pollutions, since 2003. Low efficiency of energy use and emissions control, high-speed economic growth, with 1.3 billion people, emerged large-scale and rapid growth of energy consumption and emissions. In accordance with development plan in the long term established by Development and Reform Commission, under the mandatory conditions of the supply in energy resources and environmental constraints, it is more reasonable that the proper rate of sustainable economic growth in China was approximately $7 \%-8 \%$. In recent years, many experts criticized that China's economic growth of more than $10 \%$ was at the cost of excessive consumption of energy resources and environmental pollutions. Development and Reform Commission repeatedly criticized that aimless expansion in some industries, with low efficiency of energy and resource and environmental protection level, resulted in excessive consumption of energy resources, environmental pollutions. Shortage of electricity and energy resources with higher prices indicated that the 
growth rate of the economy exceeded a reasonable limit in recent years. Some scholars pointed out that China's production capacity of iron and steel drove up prices of imported iron ore, and the economy, overheating, was being a serious state, from the angle of continuing tensity of shortage of coal, electricity and oil.

But, some scholars believe that China's economy is not overheated since the monetary policy released in 2003.China's energy and raw material prices were rising, it is just reasonable adjustments for prices that were once too low in the past long run. Higher prices in energy and raw materials did not exert a clear impact on inflation with the cost-push trend. There being no inflation, consumer price index did not rise too high, since 2003. Growth rate in urban-rural income substantially higher than the fluctuations in consumer price index, and residents' real income and consumption increased remarkably. Economic growth rate in 2003 increased to $10 \%$, demand and consumption of energy and raw materials accelerated. There has been tension in the supply of energy resources, energy and raw materials' prices going up accordingly. Since 2003, energy and raw materials' production and investment were growing in ultra-high-speed growth rate, structural contradictions, such as coal, electricity and oil shortages gradually eased. The capacity of energy, raw materials to support the economy were rapidly increasing. Fluctuations, up and down, in price indices for fuel and raw materials reflected the higher rate of economic growth under the conditions of shortage of raw materials, energy which were evolved in changes and improvements from the balance between supply and demand (Figure 4). Energy output, which was stimulated under the supply gap, grew rapidly by $14 \%$ since 2003 , gradually slowed down to $7 \%$, the state of balance between supply and demand in 2007. Capacity of producing coal and generating_electricity grew by $15 \%$, in the majority of months, from 2003 to 2007.Some departments, for example, iron and steel and non-ferrous metals grew at the rate over $20 \%$ (Figure 5, Figure 6).

Insert Figure 4 here

Insert Figure 5 here

Insert Figure 6 here

\section{References}

Chen, Yu. (1991). The choice of macroeconomic policy. The social sciences, 3.

Chang, Xiuze. China's macro-economic trends and countermeasures. Reforms and strategies, 1.

$\mathrm{Li}$, Chunguang, \& Ding. (2009). From an economic point of view interpretation of the Chinese government's macro-economic policy adjustments. Financial Times, 1.

Liu. (2009). In 2009 the orientation of China's macroeconomic policies and recommendations. Operation and Management, 1.

Lu, HanLin. (1992).The post-war US-Japan comparison of macroeconomic policies. Journal of Wuhan University (Human Sciences Edition), 3.

Wang, Jian, \& Chiron cattle. (2009). China's current macro-economic analysis of aggregate demand and growth prospects. Economic Research, reference, 1.

Wang, Xiaoguang.(2009).Challenges and Strategies-2008 Review and 2009 macro-economic prospects. Business Management, 1.

Wang, Zhengping. (2009). The global financial crisis in China's macroeconomic regulation and control countermeasures. Journal of Shenzhen University (Humanities \& Social Sciences), 1.

Zhao, Xibin. (1995). On the macro-economic policies and corporate behavior of. Journal of Wuhan University (Philosophy and Social Sciences Edition), 5.

Zheng, Chaoyu.(2009). China's macroeconomic situation and policies: 2008-2009. Economic theory and economic management, 1.

Zheng, Shigui. (1997).Macroeconomic policy analysis. Management Science Digest, 4.

Zhu, Haofei. (2009). In 2009 the top ten of China's macro-economic policy orientation of the. The contemporary economy, 1 . 
Table 1. Key index of economic growth in1998-2002 and 2003-2007 \%

\begin{tabular}{|c|c|c|c|c|c|c|c|c|c|c|}
\hline Years & GDP & CPI & $\begin{array}{c}\text { Consumption } \\
\text { retails }\end{array}$ & Investment & Exports & M2 & Loan & $\begin{array}{c}\text { Unemployment } \\
\text { rate }\end{array}$ & $\begin{array}{c}\text { Urban } \\
\text { average } \\
\text { income }\end{array}$ & $\begin{array}{c}\text { rural } \\
\text { average } \\
\text { income }\end{array}$ \\
\hline 1998 & 7.8 & -0.8 & 6.8 & 13.9 & 0.5 & 14.8 & 15.5 & 3.1 & 5.8 & 4.3 \\
\hline 1999 & 7.6 & -1.4 & 6.8 & 5.1 & 6.1 & 14.7 & 12.3 & 3.1 & 9.3 & 3.8 \\
\hline 2000 & 8.4 & 0.4 & 9.7 & 10.3 & 27.8 & 12.3 & 17.6 & 3.1 & 6.4 & 2.1 \\
\hline 2001 & 8.3 & 0.7 & 10.1 & 13.1 & 6.8 & 17.6 & 12.9 & 3.6 & 8.5 & 4.2 \\
\hline 2002 & 9.1 & -0.8 & 11.8 & 16.9 & 22.4 & 16.9 & 15.8 & 4.0 & 13.4 & 4.8 \\
\hline 2003 & 10.0 & 1.2 & 9.1 & 27.7 & 34.6 & 19.6 & 21.1 & 4.3 & 9.0 & 4.3 \\
\hline 2004 & 10.1 & 3.9 & 13.3 & 26.6 & 35.4 & 14.9 & 14.4 & 4.2 & 7.7 & 6.8 \\
\hline 2005 & 10.4 & 1.8 & 12.9 & 26.0 & 28.4 & 17.6 & 13.3 & 4.2 & 9.6 & 6.2 \\
\hline 2006 & 10.7 & 1.5 & 13.7 & 23.9 & 27.2 & 15.7 & 15.1 & 4.1 & 10.4 & 7.4 \\
\hline 2007 & 13.0 & 4.8 & 16.8 & 24.8 & 25.7 & 16.7 & 16.1 & 4.0 & 12.2 & 9.5 \\
\hline $1998-2002$ & 8.2 & -0.4 & 9.0 & 11.8 & 12.7 & 15.3 & 14.8 & 3.4 & 8.7 & 3.8 \\
\hline $2003-2007$ & 10.8 & 2.6 & 13.2 & 25.8 & 30.3 & 16.9 & 16.0 & 4.2 & 9.8 & 6.8 \\
\hline
\end{tabular}

Source: "China Statistical Yearbook 2008".

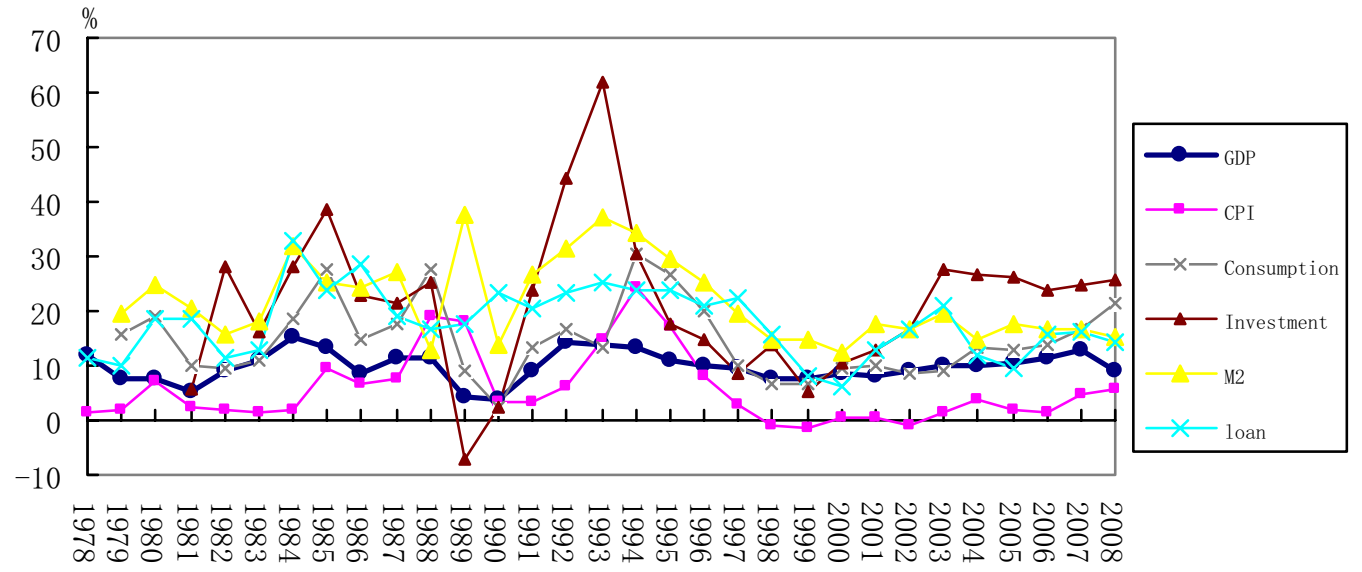

Figure 1. The main macroeconomic indicators (1978-2008)

Source: "China Statistical Yearbook 2008". 


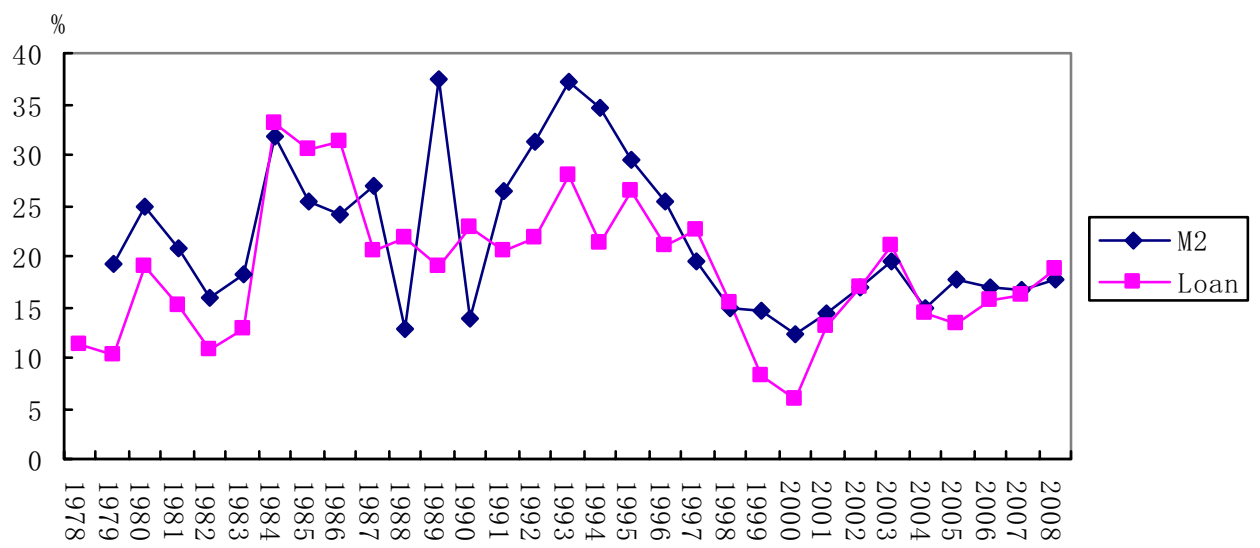

Figure 2. Growth rates of M2 and loans (1978-2008)

Source: "China Statistical Yearbook 2008".

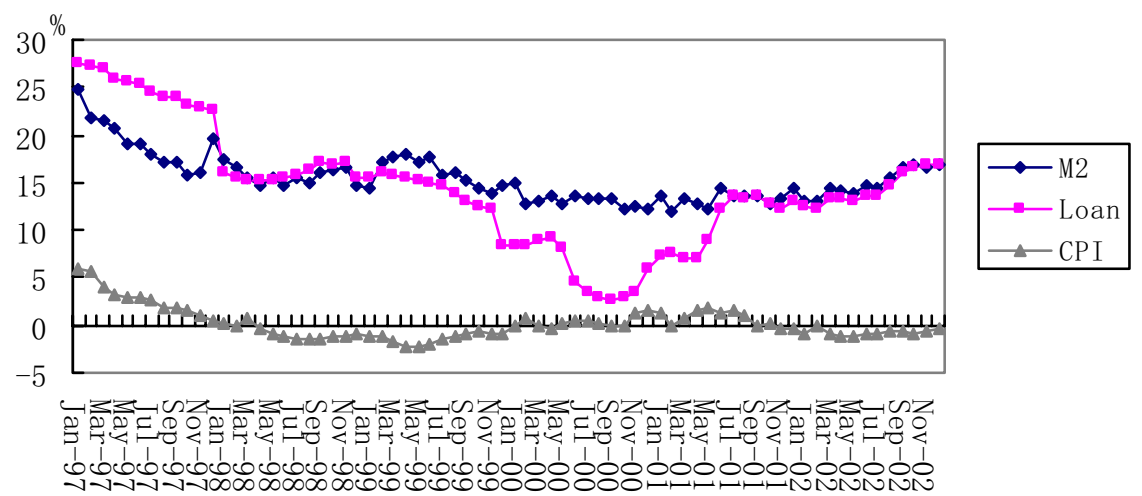

Figure 3. Monthly changes in loan and CPI (1997-2002)

Source: National Information Center for the macroeconomic database. 


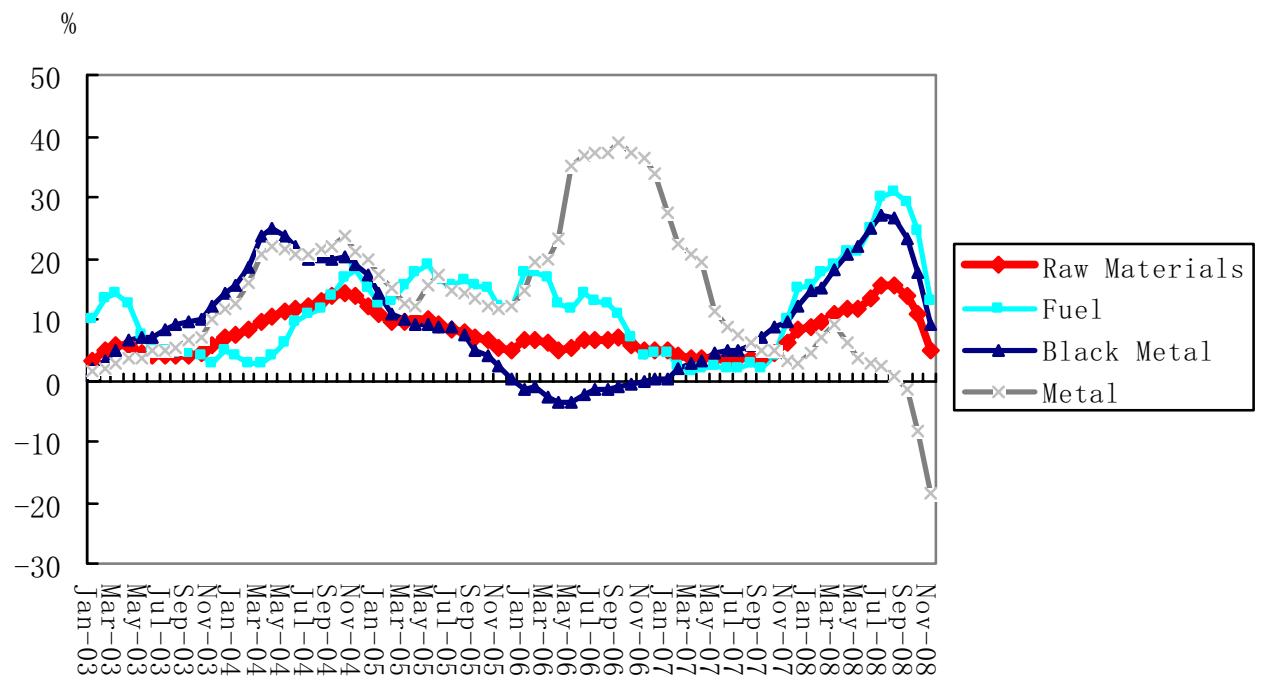

Figure 4. Monthly changes in fuel prices \& raw materials (2003-2008)

Source: National Information Center for the macroeconomic database.

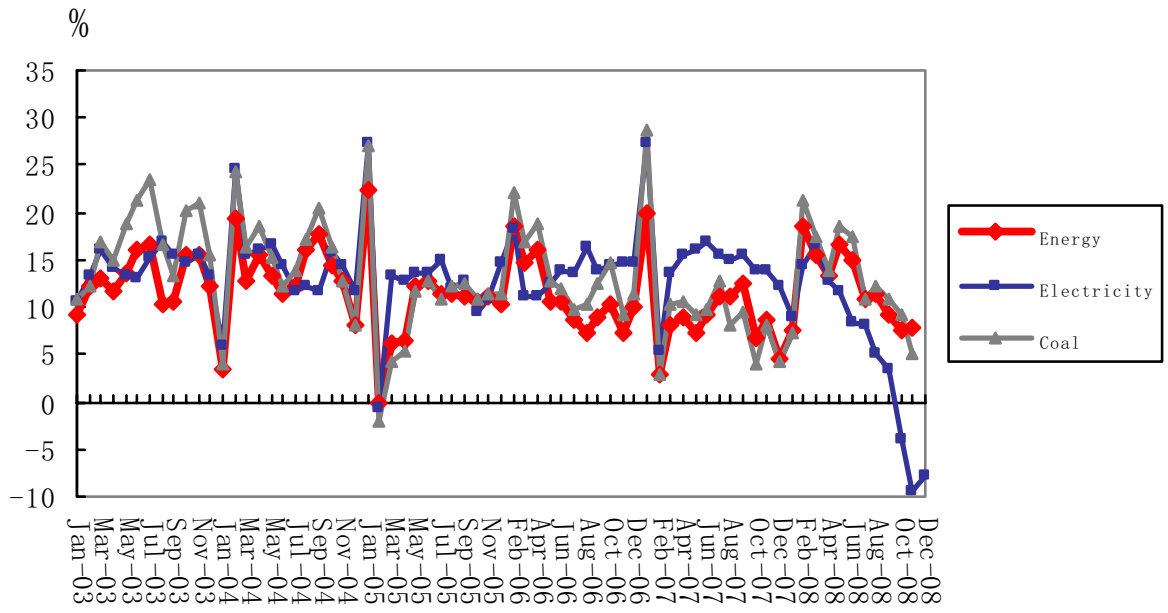

Figure 5. Monthly changes in energy production (2003-2008)

Source: National Information Center for the macroeconomic database. 


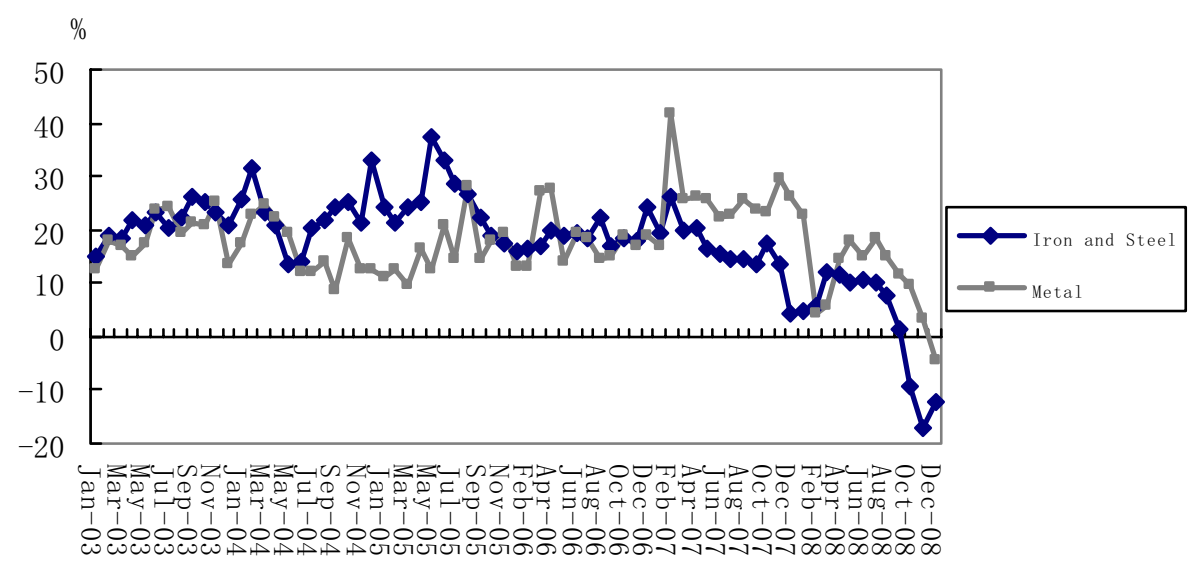

Figure 6. Monthly changes in iron and steel \& metals production (2003-2008)

Source: National Information Center for the macroeconomic database. 